\title{
Development of an International, Multicenter, Hyperbaric Oxygen Treatment Registry and Research Consortium: Protocol for Outcome Data Collection and Analysis
}

Nicole P Harlan ${ }^{1}$, MD; Judy A Ptak ${ }^{1}$, RN; Judy R Rees ${ }^{2}$, BM, BCh, MPH, PhD; Devin R Cowan², BS; Abigail M Fellows $^{2}$, MA; Judith A Kertis ${ }^{1}$, RN; Pamela M Hannigan ${ }^{1}$, RN; Janet L Peacock ${ }^{2}$, PhD; Jay C Buckey ${ }^{2}$, MD

${ }^{1}$ Center for Hyperbaric Medicine, Dartmouth-Hitchcock Medical Center, Lebanon, NH, United States

${ }^{2}$ Space Medicine Innovations Laboratory, Center for Hyperbaric Medicine, Geisel School of Medicine at Dartmouth, Lebanon, NH, United States

\section{Corresponding Author:}

Jay C Buckey, MD

Space Medicine Innovations Laboratory

Center for Hyperbaric Medicine

Geisel School of Medicine at Dartmouth

One Medical Center Drive

Lebanon, NH, 03756

United States

Phone: 16036506012

Email: jay.buckey@dartmouth.edu

\section{Abstract}

Background: Hyperbaric oxygen $\left(\mathrm{HBO}_{2}\right)$ - oxygen at pressures higher than atmospheric —is approved for 14 indications by the Undersea and Hyperbaric Medical Society. $\mathrm{HBO}_{2}$ 's main effect is to increase oxygen content in plasma and body tissues, which can counteract hypoxia or ischemia. Laboratory studies show that $\mathrm{HBO}_{2}$ has effects beyond relieving hypoxia (eg, promoting angiogenesis in irradiated tissue, anti-inflammatory effects, radiosensitization of tumors, hypoxia preconditioning, and fungal growth inhibition) and has potential to treat conditions such as inflammatory bowel disease and pyoderma gangrenosum. Lack of consistently collected outcome data on a large cohort of individuals receiving $\mathrm{HBO}_{2}$ therapy limits its use for both established and new indications. A course of therapy often involves 30-40 visits to a hyperbaric chamber, so the number of patients seen at any given center is constrained by chamber capacity. As a result, published $\mathrm{HBO}_{2}$ outcome data tend to be from small case series because few patients with a particular condition are treated at a given center. To solve this problem, a registry that collects and pools data systematically from multiple institutions has been established.

Objective: The aim of this study is to collect consistent outcome data across multiple hyperbaric centers to assess treatment effectiveness and establish a research consortium.

Methods: A consortium of hyperbaric centers who have agreed to collect consistent outcome data on all patients seen has been assembled. Data are collected at each participating center using Research Electronic Data Capture (REDCap), a web-based, data collection system used frequently for research. Standard outcome measures have been defined for each condition, which are programmed into the REDCap data collection templates. Governance is through a consortium agreement that defines data security, data sharing, publications, liability, and other issues. Centers obtain Institutional Review Board (IRB) and ethics approval to participate, either from their own institutions or by relying on the IRB at the coordinating center at Dartmouth College. Dissemination will occur through a yearly report and by publications based on the data in the registry.

Results: Early results from some common indications show significant pretreatment to posttreatment changes. Additional indications and outcome measures are being added using the procedures outlined in the consortium agreement.

Conclusions: The registry collects consistent outcome information for a therapy that needs further study and a stronger evidence base. It also overcomes the challenge of collecting data from an adequate number of patients for both established and emerging indications by combining data collection from multiple centers. The data entry requirements should be within the capabilities of existing staff at any given hyperbaric center. By using REDCap, the registry can be expanded to include detailed information on particular indications and long-term follow-up on selected patients without significantly increasing the basic data entry requirements. 
Through the registry, a network of enrolled hyperbaric centers has been established that provides the basis for a clinical trial network.

International Registered Report Identifier (IRRID)： DERR1-10.2196/18857

(JMIR Res Protoc 2020;9(8):e18857) doi: 10.2196/18857

\section{KEYWORDS}

registries; hyperbaric oxygenation; patient-reported outcome measures; registry; patient reported; outcome; measure; oxygen treatment; treatment; effectiveness; registry; health data

\section{Introduction}

Hyperbaric oxygen $\left(\mathrm{HBO}_{2}\right)$ treatment, defined as breathing $100 \%$ oxygen at pressures greater than 1.4 atmospheres absolute, is used for 14 indications approved by the Undersea and Hyperbaric Medical Society (UHMS), such as soft tissue radiation injury and enhancement of healing in selected problem wounds (see Table 1) [1]. $\mathrm{HBO}_{2}$ greatly increases the amount of oxygen dissolved in plasma and is effective at relieving hypoxia. This effect is useful in conditions such as ischemic wounds or compromised flaps or grafts, where inadequate oxygenation is a factor. Laboratory studies also suggest $\mathrm{HBO}_{2}$ has actions beyond the relief of hypoxia (eg, promoting angiogenesis in irradiated tissue, anti-inflammatory effects, radiosensitization of tumors, hypoxia preconditioning, and fungal growth inhibition) and has potential to treat other currently unapproved conditions, such as inflammatory bowel disease and pyoderma gangrenosum [2-4]. Approximately 1350 hyperbaric chamber facilities exist in the United States, and outpatient facility claims for hyperbaric services to Medicare alone totaled US $\$ 178$ million in 2015. Although $\mathrm{HBO}_{2}$ treatment is used for a variety of indications, much of the evidence to support its use is based on small trials, case series, and retrospective studies (see Table 1) [2,5-11].

This inconsistent evidence base has led to a range of opinions about when and how $\mathrm{HBO}_{2}$ should be used. For example, a common application of $\mathrm{HBO}_{2}$ is in treating radiation cystitis, which is supported by most insurance policies in the United States [12,13]. The evidence base and practice patterns are strong enough that when a randomized trial of $\mathrm{HBO}_{2}$ for radiation cystitis was attempted (ie, ClinicalTrials.gov Identifier: NCT00134628), the trial had to be closed due to poor recruitment. It was difficult to find patients who were willing to be randomized to placebo treatment and providers who were willing to refer them. In one review describing the many treatment options for radiation cystitis, the authors concluded "there are currently no adequate treatment options." They cited $\mathrm{HBO}_{2}$ response rates between $27 \%$ and $92 \%$, and recurrence rates after treatment from $8 \%$ to $63 \%$ [14]. The lower end of this response rate range suggests $\mathrm{HBO}_{2}$ should only be tried occasionally for selected patients, while the higher end argues that $\mathrm{HBO}_{2}$ should be the treatment of choice. The largest prospective study of $\mathrm{HBO}_{2}$ treatment for radiation cystitis included in that review was based on 40 patients [12]. Since that review, five Nordic university hospitals were able to complete a randomized trial for radiation cystitis, although they excluded from enrollment patients with severe ongoing bleeding (ie, the patients where the impact from $\mathrm{HBO}_{2}$ treatment would be most meaningful). The trial showed benefit from $\mathrm{HBO}_{2}$ [15].

This diversity of opinion and practice creates a difficult situation where the published evidence base is small, but advancing to large-scale clinical trials has been difficult. Also, hyperbaric centers worldwide are being asked to provide a stronger level of evidence to support the treatments they deliver. For example, the National Health Service (NHS) England will now support the routine use of $\mathrm{HBO}_{2}$ treatment only for decompression illness and gas embolism [16]. Conditions reviewed and not recommended for routine hyperbaric therapy because of the perceived lack of reliable outcome data include the UHMS-approved indications of carbon monoxide poisoning, soft tissue radiation damage, and necrotizing soft tissue infections. A new approach is needed to collect outcome data for $\mathrm{HBO}_{2}$ treatments.

The study of $\mathrm{HBO}_{2}$ treatment presents unique challenges. Because $\mathrm{HBO}_{2}$ treatment usually requires daily treatments over the course of 1-2 months in a hyperbaric chamber, single hyperbaric centers typically do not treat large numbers of patients and cannot accrue sufficient numbers to conduct credible studies. Furthermore, because patients are referred for treatment from other specialties, follow-up tends to be conducted by the referring specialist, and outcome data are not available to the hyperbaric program beyond the treatment period. Obtaining meaningful data on $\mathrm{HBO}_{2}$ outcomes requires pooling of data from multiple centers and establishing an infrastructure of centers motivated to conduct research and initiate long-term follow-up. The $\mathrm{HBO}_{2}$ Registry Consortium described here will provide this framework for urgently needed evaluative observational studies, with the potential to improve the clinical application of $\mathrm{HBO}_{2}$ dramatically. In addition, the consortium will provide an efficient platform for conducting trials on a wide range of $\mathrm{HBO}_{2}$ indications, as well as studies of the molecular underpinnings of the treatment itself. This consortium infrastructure could be used to develop the platform from which multiple studies could be conducted at much lower cost. 
Table 1. Indications for hyperbaric oxygen $\left(\mathrm{HBO}_{2}\right)$ therapy with Undersea and Hyperbaric Medical Society (UHMS) assessment of the quality and strength of evidence from the UHMS Indications report [1]

\begin{tabular}{|c|c|c|}
\hline Indication $^{\mathrm{a}}$ & UHMS assessment of evidence:quality ${ }^{\mathrm{b}}$, strength $^{\mathrm{c}}$ & Notes relevant to the registry \\
\hline \multicolumn{3}{|l|}{ UHMS-approved indications } \\
\hline Acute thermal burn injury & A, IIa & $\begin{array}{l}\text { Used only at certain centers; need to combine data } \\
\text { from centers }\end{array}$ \\
\hline Air or gas embolism & C-LD, I & $\begin{array}{l}\text { Individual centers likely to see indication only } \\
\text { occasionally }\end{array}$ \\
\hline Carbon monoxide & A, IIa & Sporadic cases at multiple centers \\
\hline Central retinal artery occlusion & C-LD, IIb & Sporadic cases at multiple centers \\
\hline Compromised grafts and flaps & C-LD, IIa & $\begin{array}{l}\text { Diverse presentations; registry good for retrospec- } \\
\text { tive as well as prospective analysis }\end{array}$ \\
\hline Crush injury and compartment syndrome & B-R, I & Used at some centers and not others \\
\hline Decompression sickness & C-LD, I & Use is concentrated at certain centers \\
\hline Delayed radiation injury & $\begin{array}{l}\text { B-R to C-LD depending on site, I to IIb depending } \\
\text { on site }\end{array}$ & $\begin{array}{l}\text { Registry can offer consistent outcome tracking } \\
\text { across centers }\end{array}$ \\
\hline $\begin{array}{l}\text { Enhancement of healing in selected prob- } \\
\text { lem wounds }\end{array}$ & $\begin{array}{l}\text { A, I for diabetic foot ulcers } \\
\text { B-NR, IIb for others }\end{array}$ & $\begin{array}{l}\text { Common use of } \mathrm{HBO}_{2} \text {; registry can offer consis- } \\
\text { tent outcome measures needed across sites }\end{array}$ \\
\hline Gas gangrene & B-NR, I & Sporadic cases at multiple centers \\
\hline $\begin{array}{l}\text { Idiopathic sudden sensorineural hearing } \\
\text { loss }\end{array}$ & A, IIa & Used regularly at some centers and not at others \\
\hline Intracranial abscess & C-LD, IIb & Sporadic cases at multiple centers \\
\hline Necrotizing soft tissue infections & B-NR, IIa & Sporadic cases at multiple centers \\
\hline Chronic refractory osteomyelitis & B-NR, IIa to IIb depending on site & Sporadic cases at multiple centers \\
\hline Severe anemia & C-LD, IIb & $\begin{array}{l}\text { Individual centers likely to see indication only } \\
\text { occasionally }\end{array}$ \\
\hline
\end{tabular}

\section{Non-UHMS-approved indications}

Calciphylaxis

\section{COVID-19 \\ Crohn disease}

Frostbite

Otitis externa

Peripheral vascular disease-related ulcer

Pneumatosis intestinalis

Pyoderma gangrenosum

Raynaud syndrome

Ulcerative colitis
Not rated

Not rated

Not rated

Not rated

Not rated

Not rated

Not rated

Not rated

Not rated

Not rated
No randomized controlled trials for any treatment modality; recommended as second-line therapy [5]

Case series show benefit $[6,7]$

Benefit seen in case reports and case series [8]

Multiple case reports show benefit; often classified as part of acute traumatic ischemia, like crush injury

Case reports show benefit; Cochrane report recommends further research [9]

$\mathrm{HBO}_{2}$ may be beneficial in selected cases

Multiple case reports show benefit [10]

Multiple case reports show benefit

Case reports and case series show benefit [11]

Recent randomized trial shows benefit for acute flares [2]

\footnotetext{
${ }^{\mathrm{a}}$ Many of these indications are only seen episodically at any given center, so a registry is important for aggregating a sufficient number of cases to draw conclusions.

${ }^{\mathrm{b}}$ Quality of evidence has five levels_-Level A: highest quality, where evidence comes from more than one randomized controlled trial, a meta-analysis of high-quality randomized controlled trials, or one or more randomized controlled trials corroborated by high-quality registry studies; Level B-R: evidence comes from randomized trials; Level B-NR: evidence comes from nonrandomized trials; Level C-LD: evidence comes from limited data; and Level C-EO: evidence comes from expert opinion.

${ }^{\mathrm{c}}$ Strength of evidence is classified as Class I: Strong; Class IIa: Moderate; Class IIb: Weak; Class III: No benefit; and Class III: Harm.
} 
${ }^{\mathrm{d}}$ COVID-19: coronavirus disease 2019.

Beyond the fundamental question of whether $\mathrm{HBO}_{2}$ treatment should be recommended for given indications, the $\mathrm{HBO}_{2}$ community needs data to answer more detailed questions, such as: Are some forms of radiation injury (eg, brain radionecrosis) more or less responsive than others to $\mathrm{HBO}_{2}$ treatment? Are some patients more likely than others to benefit from $\mathrm{HBO}_{2}$ for a given indication, and can those patients be identified? Having identified the patients most likely to benefit from treatment, can trials be designed more effectively to test $\mathrm{HBO}_{2}$ treatment (eg, crossover trials)? A well-designed registry can provide the data required to answer these questions.

\section{Methods}

\section{Overview}

This paper outlines the development of an international, multicenter, prospective registry consortium. A center joins the consortium by signing the consortium agreement. This agreement covers membership, governance, data sharing requirements, use of member data, publications, intellectual property, liability, confidentiality, and insurance. Data are collected using Research Electronic Data Capture (REDCap), a widely available, easily accessible, Health Insurance Portability and Accountability Act (HIPAA)-compliant, web-based data collection system [17]. Each participating center determines its own start date for data collection (ie, reference date) and records baseline data for every patient referred to the treatment center, whether or not treatment is indicated for, or accepted by, the patient after that start date. Patients included in the registry are those patients who have been evaluated for possible treatment of any UHMS-approved condition, or any non-UHMS-approved condition, including those who are part of research studies or trials. The registry gathers data on whether the evaluation determined that treatment was contraindicated, indicated and scheduled, or indicated but declined by the patient.

Each center's participation is overseen by its own US Institutional Review Board (IRB) or the country-specific equivalent, or a center can opt to rely on the Dartmouth Committee for the Protection of Human Subjects (ie, the Dartmouth IRB). The REDCap-based data collection template is the same at all centers, so all centers collect the same outcome measures. Quarterly, each center performs a deidentified data download from their REDCap database to the coordinating center's REDCap database at Dartmouth College. These deidentified data from each center are combined into a single REDCap database, which is the multicenter data registry. Optional consent for longer-term follow-up is being pilot tested at one center.

\section{Data Collected}

The design approach to the registry is to create a system that can be used at any hyperbaric center. This means the system must be low cost and not require excessive staff effort. Although gathering data from electronic medical record systems is desirable to avoid repeated data entry, this is not practical for this project due to the diversity of medical record systems and the level of effort and funding required to standardize and update outcome measures and procedures among them. To minimize staff effort, data entry needs to be minimal, which means extensive data on comorbid conditions, medications, and medical history cannot be collected. Instead, the registry has to focus on a few key outcome measures whose data any center can collect and enter reliably. For studies using registry data where more information on the individual patients is needed, an interested investigator can obtain IRB or ethics approval to work with more detailed data at the individual centers using procedures outlined in the consortium agreement.

The registry database was initially designed by a consensus of founding members of the $\mathrm{HBO}_{2}$ research consortium - the Geisel School of Medicine at Dartmouth in Hanover, New Hampshire, and the Dartmouth-Hitchcock Medical Center in Lebanon, New Hampshire-and core data are collected for UHMS-approved and some nonapproved conditions. Data are collected using four main data collection instruments (see Table 2). The Demographics instrument collects demographic information as well as information on insurance and distance traveled. The Pre Treatment Information instrument collects information on the condition being treated, treatments prescribed and administered, and subjective and objective measurements of the patient's status at treatment start. A quality-of-life measure-the EuroQol, 5-dimension, 5-level (EQ-5D-5L) - is also administered at baseline on all patients $[18,19]$ as part of the Pre Treatment Information instrument. The Pre Surgical Information instrument collects subjective and objective measures of the patient's status prior to a surgical intervention (eg, tooth extraction) if one is performed. The Treatment and Outcomes instrument repeats information collection of the Pre Treatment Information outcome measures, records the actual treatment given, asks about complications, and repeats the quality-of-life questionnaire.

Both indication-specific outcomes and general outcomes are collected, including $\mathrm{HBO}_{2}$ treatment complications (eg, changes in refraction, seizures, pneumothorax, confinement anxiety, barotrauma, and placement of pressure-equalization tubes in the ear). Wherever possible, common objective outcome measures are used. The registry uses validated questionnaires that have supporting evidence in the literature (eg, the Common Terminology Criteria for Adverse Events [CTCAE] hematuria grading scale for radiation cystitis and the European Organisation for Research and Treatment of Cancer [EORTC] Quality of Life Questionnaire Head and Neck [QLQ-H\&N35] for head and neck symptoms) [20,21] as well as some questionnaires that were custom developed for the registry (see Table 2) [22-24]. Factors that might affect the effectiveness of the therapy are also collected (eg, diabetes, smoking, and other nicotine use). Future plans, including long-term follow-up and linkage to cancer registries and vital status data, depend on future funding. Table 3 lists the parameters measured $[25,26]$. 
Table 2. Data collection instruments and questionnaires used in the registry. Patient-reported outcomes are used in the registry whenever possible.

\begin{tabular}{|c|c|}
\hline Instruments and questionnaires & Details $^{\mathrm{a}}$ \\
\hline \multicolumn{2}{|l|}{ Data collection instruments } \\
\hline Demographics & $\begin{array}{l}\text { Age, race, ethnicity, biological sex, insurance, and driving distance; personal health information is } \\
\text { only kept at individual centers }\end{array}$ \\
\hline Pre Treatment Information & $\begin{array}{l}\text { Referral reason, urgency, diabetes, smoking, nicotine, indication, baseline questionnaires and outcome } \\
\text { information, EQ-5D-5L } \text {, and prescribed treatment }\end{array}$ \\
\hline Pre Surgical Information & $\begin{array}{l}\text { Outcome measures prior to intervention if one is performed (eg, tooth extraction, mandibular recon- } \\
\text { struction, etc) }\end{array}$ \\
\hline Treatment and Outcomes & Treatment given, complications experienced, and outcome measures \\
\hline \multicolumn{2}{|l|}{ Questionnaires used in the registry } \\
\hline Bladder Questionnaire (radiation cystitis) & $\begin{array}{l}\text { Seven questions from the Urinary Distress Inventory } 6 \text { plus one custom registry question on urinary } \\
\text { bleeding [24] }\end{array}$ \\
\hline Bowel Symptoms Questionnaire & Nine questions custom developed for the registry \\
\hline Head and Neck Questionnaire & 37 questions selected from the EORTC $^{\mathrm{c}} \mathrm{QLQ}^{\mathrm{H}} \& \mathrm{~N} 35^{\mathrm{d}}$ [23] and the GRIX ${ }^{\mathrm{e}}$ questionnaire [22] \\
\hline $\begin{array}{l}\text { Laryngeal Soft Tissue Radionecrosis Ques- } \\
\text { tionnaire }\end{array}$ & Two questions based on the Chandler [20] and RTOG ${ }^{\mathrm{f}}$ scales [21] \\
\hline Perianal Crohn's Symptom Index & 11 questions custom developed for the registry \\
\hline
\end{tabular}

${ }^{a}$ Details of data collection instruments include the types of data collected; details of questionnaires used in the study; and the sources used to develop the questionnaires.

${ }^{\mathrm{b}}$ EQ-5D-5L: EuroQol, 5-dimension, 5-level.

${ }^{c}$ EORTC: European Organisation for Research and Treatment of Cancer.

${ }^{\mathrm{d}}$ QLQ-H\&N35: Quality of Life Questionnaire Head and Neck.

${ }^{\text {e}}$ GRIX: Groningen Radiotherapy-Induced Xerostomia.

${ }^{\mathrm{f}}$ RTOG: Radiation Therapy Oncology Group. 
Table 3. Indications for hyperbaric oxygen $\left(\mathrm{HBO}_{2}\right)$ treatment and outcomes measured for the registry.

\begin{tabular}{l} 
Condition \\
\hline Undersea and Hyperbaric Medical Society (UHMS)-a \\
Acute ischemia (not crush injury or compartment \\
syndrome) \\
Acute thermal burn injury \\
Air or gas embolism \\
Carbon monoxide \\
Central retinal artery occlusion \\
Compromised grafts and flaps \\
Crush injury and compartment syndrome \\
Decompression sickness \\
Delayed radiation injury \\
Brain \\
Larynx \\
Bladder \\
Bowel \\
Jaw
\end{tabular}

Pre- and posttreatment outcome measurements ${ }^{\mathrm{a}}$

pproved conditions

Assessment of cyanosis in affected areas pre- and posttreatment and amputations posttreatment

Number of wounds and wound measurements

Glasgow Coma Scale score for brain events, troponin for cardiac events, and six-level outcome measure for all

Narrative on treatment and outcome

Visual acuity (right and left)

Graft and flap assessment (necrosis and color), number of wounds, and wound measurements

Location, number of wounds, and wound measurements

Six-level patient outcome measure

Nine-Hole Peg Test and Trail-Making Test

Laryngeal Soft Tissue Radionecrosis Questionnaire and Head and Neck Questionnaire

Hematuria grade and Bladder Questionnaire

Bowel Questionnaire

Exposed bone percentage coverage if exposed bone present, osteoradionecrosis grade [25], tooth complications after extraction, and Head and Neck Questionnaire

Enhancement of healing in selected problem wounds Number of wounds, wound measurements, Wagner grade, and Strauss score [26]

Gas gangrene

White blood cell count, number of wounds, wound measurements, and number of surgical interventions

Idiopathic sudden sensorineural hearing loss

Four-frequency pure-tone average and word recognition score

Intracranial abscess

Number of surgical interventions

Necrotizing soft tissue infections

White blood cell count, number of wounds, wound measurements, and number of surgical interventions

Chronic refractory osteomyelitis

White blood cell count, C-reactive protein, and number of surgical interventions

Severe anemia

Hemoglobin; markers of end-organ damage; and narrative on treatment, complications, and outcome

\section{Conditions not currently UHMS approved}

Calciphylaxis

COVID-19
Crohn disease

Frostbite

Malignant otitis externa

Peripheral vascular disease-related ulcer

Pneumatosis intestinalis

Pyoderma gangrenosum

Raynaud syndrome

Ulcerative colitis
Location, number of wounds, wound measurements, number of surgical interventions, and subjective assessment at end of treatment

Pulse oximetry pre- and posttreatment, respiratory rate pre- and posttreatment, and pretreatment oxygen

Perianal Crohn's Symptom Index and Bowel Questionnaire

Number of wounds, wound measurements, and number of surgical interventions

Narrative on treatment and outcome

Number of wounds, wound measurements, and number of surgical interventions

Narrative on treatment and outcome

Number of wounds, wound measurements, and number of surgical interventions

Number of wounds, wound measurements, and number of surgical interventions

Bowel Questionnaire

${ }^{a}$ All patients will complete a quality-of-life questionnaire—the EuroQol, 5-dimension, 5-level (EQ-5D-5L) [19]—at the start and end of treatment. Text entries are available for all indications to provide more detail about the cases.

${ }^{\mathrm{b}}$ COVID-19: coronavirus disease 2019. 


\section{Governance}

The $\mathrm{HBO}_{2}$ Registry Consortium includes member institutions fulfilling the requirements as shown in Textbox 1. A steering committee is responsible for the governance of the registry. The Geisel School of Medicine at Dartmouth and the Dartmouth-Hitchcock Medical Center are the founding members of the consortium and each have representatives on the steering committee. The steering committee also includes a representative from each participating center. By a majority vote, with affirmative votes from the founding members, the steering committee has the authority to set the strategic direction for the registry, admit or remove members, set membership fees, establish policies, and relocate the registry. Member-initiated research protocols are approved by a majority vote of the steering committee. The committee also votes on any changes to the REDCap data collection instruments. The steering committee meets annually at the UHMS annual meeting, where changes and modifications to the registry are discussed and voted upon. Template IRB application materials are freely shared between participating centers.

Textbox 1. Requirements and activities of participating centers of the HBO2 Registry Consortium.

Center characteristic:

- Hyperbaric oxygen $\left(\mathrm{HBO}_{2}\right)$ treatment program

Administrative requirements:

- Ethics Committee approval, either by relying on Dartmouth or at own center

- Execution of consortium agreement, which includes agreement to share deidentified data with coordinating center and willingness to have data used for registry purposes

- Installation of, or access to, Research Electronic Data Capture (REDCap) database at the center or establishment of procedures and authorization to enter patient data securely into REDCap database hosted by another participating center

Data collection activities:

- Patient informed consent or waived consent, depending on Ethics Committee requirement

- Prospective data entry for all patients evaluated at the center; if consent is not waived, need to have $95 \%$ or greater participation over a year

- Administration of indication-specific questionnaires and/or collection of outcome measurement data before and after treatment

- Completion of annual audit and quality assurance processes; responsiveness to feedback on data quality and attainment of defined minimum data-quality standards

- Quarterly submission of deidentified patient data to coordinating center at Dartmouth College

- Option to participate in research studies, grant writing, or fundraising efforts

\section{Statistical Analysis}

Descriptive analyses will be conducted to describe the baseline characteristics and outcomes of patients with each indication, overall and by center, including the numbers, proportions, and confidence intervals for the following: patients with each indication for treatment; those evaluated who were not treated or who were partially treated and the reasons why; baseline characteristics, including referral information and baseline outcome measures; treatments given; occurrence of each type of side effect; and outcome measures at the end of treatment with change scores and relative change scores, as appropriate. For measures with numerical scores, we will assess absolute and relative changes; for other measures, we will report outcomes in terms of the proportions with symptom resolution, improvement, no change, or deterioration. Factors associated with key outcomes will be explored using multifactorial analyses where sample size is sufficient for models to be stable. All results will be presented and discussed in terms of estimates and $95 \%$ confidence intervals to avoid focusing on $P$ values alone.

\section{Results}

Data collection started within the registry at the Dartmouth-Hitchcock Medical Center as a pilot project in 2012. During this time, the consortium agreement was developed and processes were established to enroll other centers. In 2019, four additional centers began entering patient data. Currently, the registry has 919 individual patient entries from four centers, with the majority from the Dartmouth-Hitchcock Medical Center $(n=621)$. Over time, the registry is gradually collecting sufficient data to robustly explore changes before and after $\mathrm{HBO}_{2}$ treatment. Figure 1, for example, shows the results for the Head and Neck Questionnaire before and after $\mathrm{HBO}_{2}$ treatment. Figure 2 shows changes in patient-reported symptoms of xerostomia (ie, dry mouth) after receiving $\mathrm{HBO}_{2}$ treatment. These responses are important because whether $\mathrm{HBO}_{2}$ treatment has an effect on xerostomia has been a longstanding question in the $\mathrm{HBO}_{2}$ field [27]. Figure 3 shows changes in the hematuria score for those patients undergoing treatment with $\mathrm{HBO}_{2}$ for radiation cystitis. Figure 4 shows the experience to date for patients treated for idiopathic sudden sensorineural hearing loss. These preliminary results show that the registry is useful for tracking trends in outcomes and patient-reported symptoms after $\mathrm{HBO}_{2}$ 
treatment. As further patient experiences are collected, these characteristics of those patients who responded well and of those data will also be used in retrospective analyses to determine the who did not.

Figure 1. Delayed radiation injury. Scores on the Head and Neck Questionnaire before and after hyperbaric oxygen $\left(\mathrm{HBO}_{2}\right)$ are shown: lower scores indicate fewer symptoms. This questionnaire is administered to any patient who had experienced head and neck radiation and is being treated for radiation injury in the head and neck region. Although responses vary between patients, results show lower scores posttreatment (16.9 pretreatment to 14.3 posttreatment, $P=.03$, Wilcoxon signed-rank test). By identifying patients who did not respond or who worsened, these data can guide further analyses.

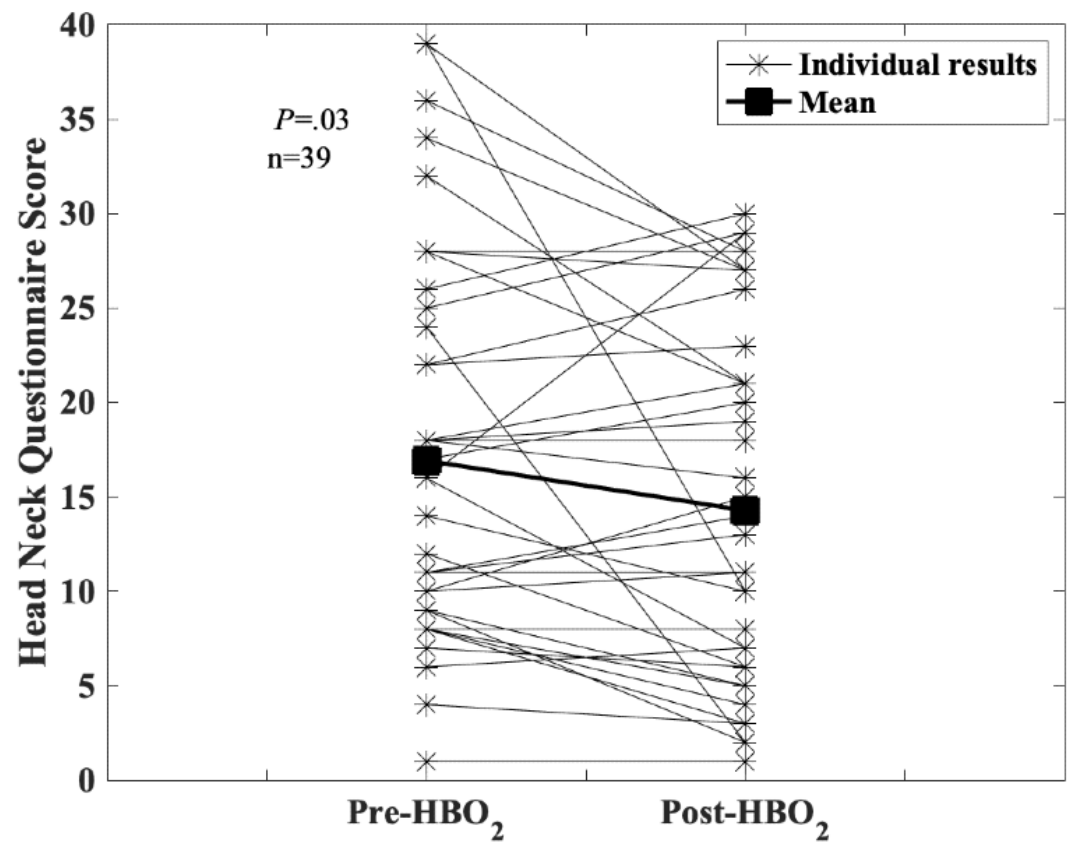

Figure 2. Delayed radiation injury. Scores on the xerostomia (ie, dry mouth) questions within the Head and Neck Questionnaire are shown: lower scores indicate fewer symptoms. Dry mouth is a common complication of head and neck radiation, and whether hyperbaric oxygen $\left(\mathrm{HBO}_{2}\right)$ helps with this symptom is an open question. Early results from the registry suggest improvement (11.9 pretreatment to 8.9 posttreatment, $P=.01$, Wilcoxon signed-rank test).

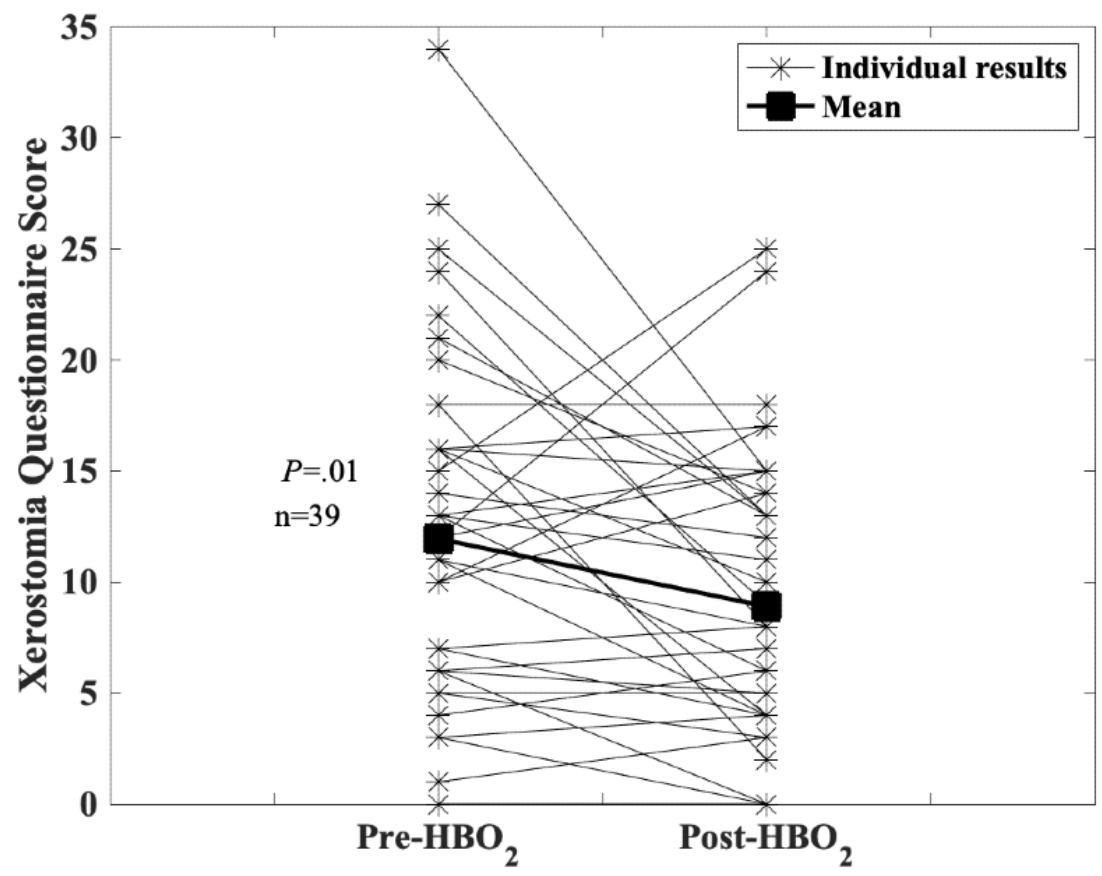


Figure 3. Delayed radiation injury, radiation cystitis. Scores on the hematuria scale before and after hyperbaric oxygen $\left(\mathrm{HBO}_{2}\right)$ treatment are shown: $0=$ no hematuria, $1=$ microscopic hematuria, $2=$ occasional macroscopic hematuria, $3=$ frequent macroscopic hematuria, and $4=$ severe hemorrhagic cystitis . Most patients see an improvement in hematuria score ( 2.5 pretreatment to 1.0 posttreatment, $P<.001$, Wilcoxon signed-rank test). As the number of entries in the registry grows, these data may be useful for assessing the number of treatments needed for successful outcomes.

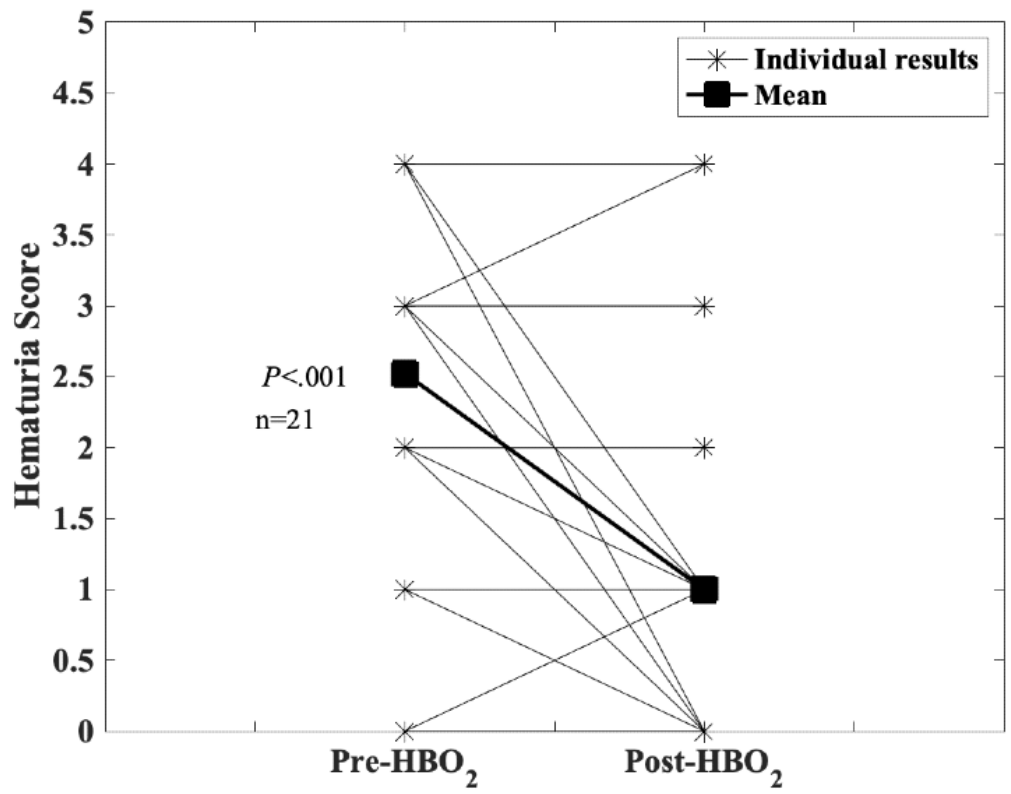

Figure 4. Idiopathic sudden sensorineural hearing loss. Four-frequency pure-tone averages on audiometry before and after hyperbaric oxygen treatment $\left(\mathrm{HBO}_{2}\right)$ are shown: a lower number indicates an improvement in hearing. Most patients are experiencing an improvement in audiometric thresholds ( $89.9 \mathrm{~dB}$ hearing loss [HL] pretreatment to $72.3 \mathrm{~dB}$ HL posttreatment, $P=.03$, Wilcoxon signed-rank test). As the number of cases in the registry grows, these data could be used to assess how long after the hearing loss $\mathrm{HBO}_{2}$ may be useful.

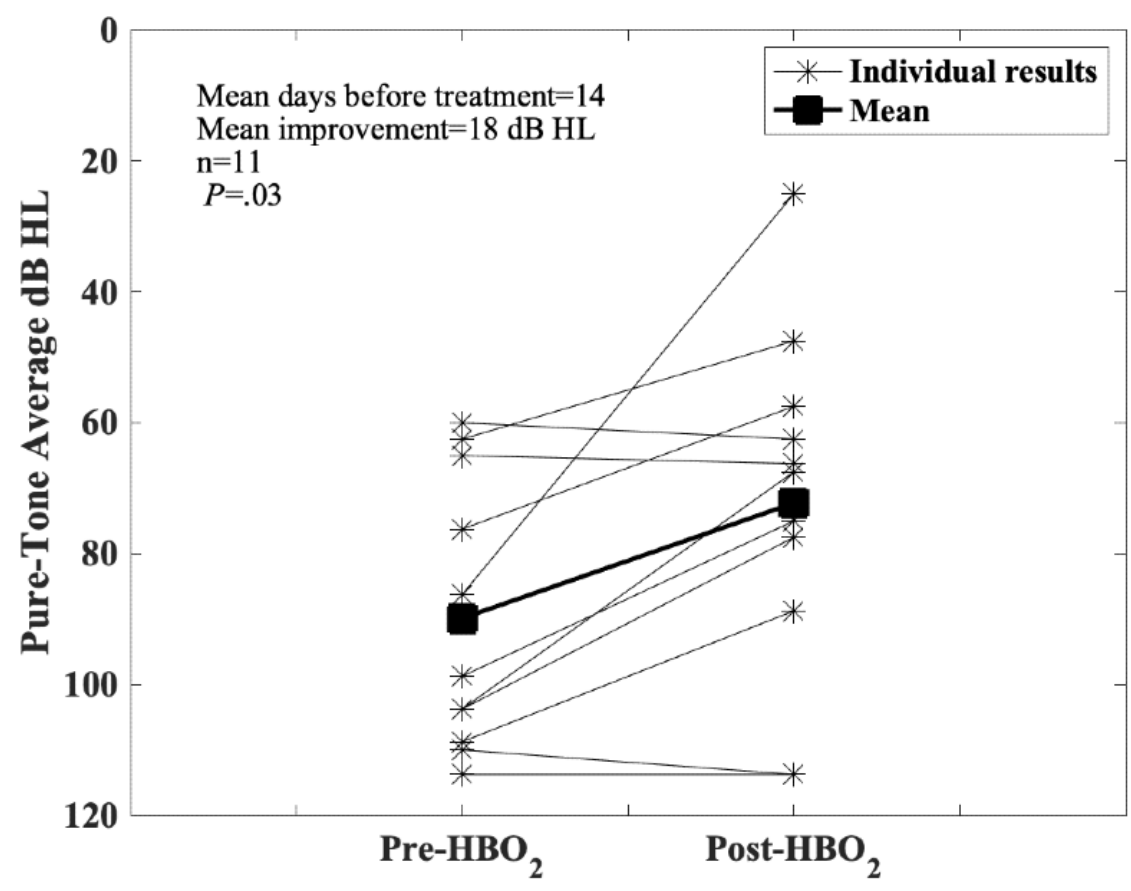

\section{Discussion}

\section{Principal Findings}

An $\mathrm{HBO}_{2}$ treatment outcomes registry is feasible and can provide consistently recorded outcomes from $\mathrm{HBO}_{2}$ treatments at multiple centers. Initial analyses of some of the outcome data are already showing significant changes after $\mathrm{HBO}_{2}$ treatment.

\section{Strengths of the Registry}

A key strength of the registry is its use of REDCap [17], a free, secure, web-based, data collection system used to build and manage online surveys and databases in more than 3964 centers worldwide. The $\mathrm{HBO}_{2}$ REDCap database has been pilot tested and revised at the coordinating center for 6 years, and core variables have been collected on UHMS-approved indications for $\mathrm{HBO}_{2}$ treatment, as well as some non-UHMS-approved 
indications. The database includes 1996 variables, many of which are disease specific and are programmed to appear only for particular indications or situations (ie, during data entry, a staff member will only be entering data on a small subset of the variables available). Data entry takes an average of 15 minutes per case, distributed over several clinical visits. The template for the database can be exported to Excel, emailed to another center, and easily uploaded to create an identical registry that is ready for data entry. REDCap provides the ability to perform a deidentified data export from each participating center. This is sent to a central, pooled REDCap database at the Geisel School of Medicine at Dartmouth. Because of the simplicity of the software and the relatively low burden of data entry, the registry is relatively inexpensive for new centers to install and maintain. Because only deidentified data are pooled, the risk to participants is minimal.

\section{Limitations of the Registry}

At present, the registry is following individuals who receive $\mathrm{HBO}_{2}$ treatment, and a registry of similar patients with similar conditions who are not receiving $\mathrm{HBO}_{2}$ treatment does not exist.
Therefore, there is no way to compare outcomes from $\mathrm{HBO}_{2}$ treatment directly with outcomes from similar patients who did not receive the treatment. As the registry grows, an additional limitation will be funding, which will be needed to maintain a system of data-quality oversight, analysis, longer-term follow-up, and other registry-related activities.

\section{Conclusions}

An outcome-focused registry for $\mathrm{HBO}_{2}$ treatment is needed urgently to provide both patients and providers with the information they need to decide whether and how to use $\mathrm{HBO}_{2}$ treatment. To be successful, this registry must be practical, easy to use, and easily expandable. The registry described here meets these requirements. The data entry requirements are not excessive and should be within the capabilities of existing staff at any given hyperbaric center. Also, by using REDCap, the registry can be expanded to include detailed information on particular indications and long-term follow-up on selected patients without significantly increasing the basic data entry requirements.

\section{Acknowledgments}

The project directors of the Multicenter Hyperbaric Medicine Outcome Registry would like to acknowledge and thank the Department of Medicine at the Geisel School of Medicine at Dartmouth and the Dartmouth-Hitchcock Medical Center for its funding support through the Department of Medicine Scholarship Enhancement in Academic Medicine (SEAM) Award Program. The authors would also like to thank all the individuals who assisted with the development of the registry. Susan Reetz, RN, was essential to implementing the registries in hyperbaric operations. We thank John Higgins for his help with REDCap.

\section{Conflicts of Interest}

None declared.

\section{Multimedia Appendix 1}

Presentation of the study. [PPTX File, 2418 KB-Multimedia Appendix 1]

\section{References}

1. Undersea and Hyperbaric Medical Society. In: Moon RE, editor. Hyperbaric Oxygen Therapy Indications. 14th edition. North Palm Beach, FL: Best Publishing; 2019.

2. Dulai PS, Buckey JC, Raffals LE, Swoger JM, Claus PL, O Toole K, et al. Hyperbaric oxygen therapy is well tolerated and effective for ulcerative colitis patients hospitalized for moderate-severe flares: A phase 2A pilot multi-center, randomized, double-blind, sham-controlled trial. Am J Gastroenterol 2018 Oct;113(10):1516-1523. [doi: 10.1038/s41395-018-0005-z] [Medline: 29453383]

3. Thom SR. Hyperbaric oxygen: Its mechanisms and efficacy. Plast Reconstr Surg 2011 Jan;127 Suppl 1:131S-141S [FREE Full text] [doi: 10.1097/PRS.0b013e3181fbe2bf] [Medline: 21200283]

4. Seo HI, Lee H, Han KH. Hyperbaric oxygen therapy for pyoderma gangrenosum associated with ulcerative colitis. Intest Res 2018 Jan;16(1):155-157 [FREE Full text] [doi: 10.5217/ir.2018.16.1.155] [Medline: 29422812]

5. Nigwekar SU, Kroshinsky D, Nazarian RM, Goverman J, Malhotra R, Jackson VA, et al. Calciphylaxis: Risk factors, diagnosis, and treatment. Am J Kidney Dis 2015 Jul;66(1):133-146 [FREE Full text] [doi: 10.1053/j.ajkd.2015.01.034] [Medline: 25960299]

6. Harch PG. Hyperbaric oxygen treatment of novel coronavirus (COVID-19) respiratory failure. Med Gas Res 2020;10(2):61-62. [doi: 10.4103/2045-9912.282177] [Medline: $\underline{32541128]}$

7. Thibodeaux K, Speyrer M, Raza A, Yaakov R, Serena TE. Hyperbaric oxygen therapy in preventing mechanical ventilation in COVID-19 patients: A retrospective case series. J Wound Care 2020 May 01;29(Sup5a):S4-S8. [doi: 10.12968/jowc.2020.29.Sup5a.S4] [Medline: 32412891] 
8. Dulai PS, Gleeson MW, Taylor D, Holubar SD, Buckey JC, Siegel CA. Systematic review: The safety and efficacy of hyperbaric oxygen therapy for inflammatory bowel disease. Aliment Pharmacol Ther 2014 Jun;39(11):1266-1275 [FREE Full text] [doi: 10.1111/apt.12753] [Medline: 24738651]

9. Phillips JS, Jones SEM. Hyperbaric oxygen as an adjuvant treatment for malignant otitis externa. Cochrane Database Syst Rev 2013 May 31(5):CD004617. [doi: 10.1002/14651858.CD004617.pub3] [Medline: 23728650]

10. Feuerstein JD, White N, Berzin TM. Pneumatosis intestinalis with a focus on hyperbaric oxygen therapy. Mayo Clin Proc 2014 May;89(5):697-703. [doi: 10.1016/j.mayocp.2014.01.026] [Medline: 24797647]

11. Dowling GB, Copeman PW, Ashfield R. Raynaud's phenomenon in scleroderma treated with hyperbaric oxygen. Proc R Soc Med 1967 Dec;60(12):1268-1269 [FREE Full text] [Medline: 6066573]

12. Bevers RF, Bakker DJ, Kurth KH. Hyperbaric oxygen treatment for haemorrhagic radiation cystitis. Lancet 1995 Sep 23;346(8978):803-805. [doi: 10.1016/s0140-6736(95)91620-2] [Medline: 7674746]

13. Chong KT, Hampson NB, Corman JM. Early hyperbaric oxygen therapy improves outcome for radiation-induced hemorrhagic cystitis. Urology 2005 Apr;65(4):649-653. [doi: 10.1016/j.urology.2004.10.050] [Medline: 15833500]

14. Rajaganapathy BR, Jayabalan N, Tyagi P, Kaufman J, Chancellor MB. Advances in therapeutic development for radiation cystitis. Low Urin Tract Symptoms 2014 Jan;6(1):1-10. [doi: 10.1111/luts.12045] [Medline: 26663493]

15. Oscarsson N, Müller B, Rosén A, Lodding P, Mölne J, Giglio D, et al. Radiation-induced cystitis treated with hyperbaric oxygen therapy (RICH-ART): A randomised, controlled, phase 2-3 trial. Lancet Oncol 2019 Nov;20(11):1602-1614. [doi: 10.1016/S1470-2045(19)30494-2] [Medline: 31537473]

16. NHS England Specialised Commissioning. NHS England Response to the HBOT Service Review Consultation. London, UK: National Health Service (NHS) England; 2018 Oct 24. URL: https://www.engage.england.nhs.uk/consultation/ reviewing-hyperbaric-oxygen-services/user uploads/hyperbaric-oxygen-services-consultation-response-october-2018.pdf [accessed 2020-08-05]

17. Harris PA, Taylor R, Thielke R, Payne J, Gonzalez N, Conde JG. Research electronic data capture (REDCap): A metadata-driven methodology and workflow process for providing translational research informatics support. J Biomed Inform 2009 Apr;42(2):377-381 [FREE Full text] [doi: 10.1016/j.jbi.2008.08.010] [Medline: 18929686]

18. Herdman M, Gudex C, Lloyd A, Janssen M, Kind P, Parkin D, et al. Development and preliminary testing of the new five-level version of EQ-5D (EQ-5D-5L). Qual Life Res 2011 Dec;20(10):1727-1736 [FREE Full text] [doi: 10.1007/s11136-011-9903-x] [Medline: 21479777]

19. Janssen MF, Pickard AS, Golicki D, Gudex C, Niewada M, Scalone L, et al. Measurement properties of the EQ-5D-5L compared to the EQ-5D-3L across eight patient groups: A multi-country study. Qual Life Res 2013 Sep;22(7):1717-1727 [FREE Full text] [doi: 10.1007/s11136-012-0322-4] [Medline: 23184421]

20. Chandler JR. Radiation fibrosis and necrosis of the larynx. Ann Otol Rhinol Laryngol 1979;88(4 Pt 1):509-514. [doi: 10.1177/000348947908800410] [Medline: 475247]

21. Filntisis GA, Moon RE, Kraft KL, Farmer JC, Scher RL, Piantadosi CA. Laryngeal radionecrosis and hyperbaric oxygen therapy: Report of 18 cases and review of the literature. Ann Otol Rhinol Laryngol 2000 Jun;109(6):554-562. [doi: 10.1177/000348940010900605] [Medline: 10855566 ]

22. Beetz I, Burlage FR, Bijl HP, Hoegen-Chouvalova O, Christianen MEMC, Vissink A, et al. The Groningen Radiotherapy-Induced Xerostomia questionnaire: Development and validation of a new questionnaire. Radiother Oncol 2010 Oct;97(1):127-131. [doi: 10.1016/j.radonc.2010.05.004] [Medline: 20541272]

23. Bjordal K, Kaasa S. Psychometric validation of the EORTC Core Quality of Life Questionnaire, 30-item version and a diagnosis-specific module for head and neck cancer patients. Acta Oncol 1992;31(3):311-321. [doi: 10.3109/02841869209108178] [Medline: 1622651]

24. Uebersax JS, Wyman JF, Shumaker SA, McClish DK, Fantl JA. Short forms to assess life quality and symptom distress for urinary incontinence in women: The Incontinence Impact Questionnaire and the Urogenital Distress Inventory. Continence Program for Women Research Group. Neurourol Urodyn 1995;14(2):131-139. [doi: 10.1002/nau.1930140206] [Medline: 7780440]

25. Notani K, Yamazaki Y, Kitada H, Sakakibara N, Fukuda H, Omori K, et al. Management of mandibular osteoradionecrosis corresponding to the severity of osteoradionecrosis and the method of radiotherapy. Head Neck 2003 Mar;25(3):181-186. [doi: 10.1002/hed.10171] [Medline: 12599284]

26. Strauss MB, Moon H, Busch JA, Jones CK, Nhan L, Miller S, et al. Reliability assessment of an innovative wound score. Wounds 2016 Jun;28(6):206-213 [FREE Full text] [Medline: 27377611]

27. Sherlock S, Way M, Tabah A. Hyperbaric oxygen treatment for the management of radiation-induced xerostomia. J Med Imaging Radiat Oncol 2018 Dec;62(6):841-846. [doi: 10.1111/1754-9485.12789] [Medline: $\underline{\text { 30113763] }}$

\section{Abbreviations}

CTCAE: Common Terminology Criteria for Adverse Events

EORTC: European Organisation for Research and Treatment of Cancer

EQ-5D-5L: EuroQol, 5-dimension, 5-level 
$\mathrm{HBO}_{2}$ : hyperbaric oxygen

HIPAA: Health Insurance Portability and Accountability Act

IRB: Institutional Review Board

NHS: National Health Service

QLQ-H\&N35: Quality of Life Questionnaire Head and Neck

REDCap: Research Electronic Data Capture

SEAM: Scholarship Enhancement in Academic Medicine

UHMS: Undersea and Hyperbaric Medical Society

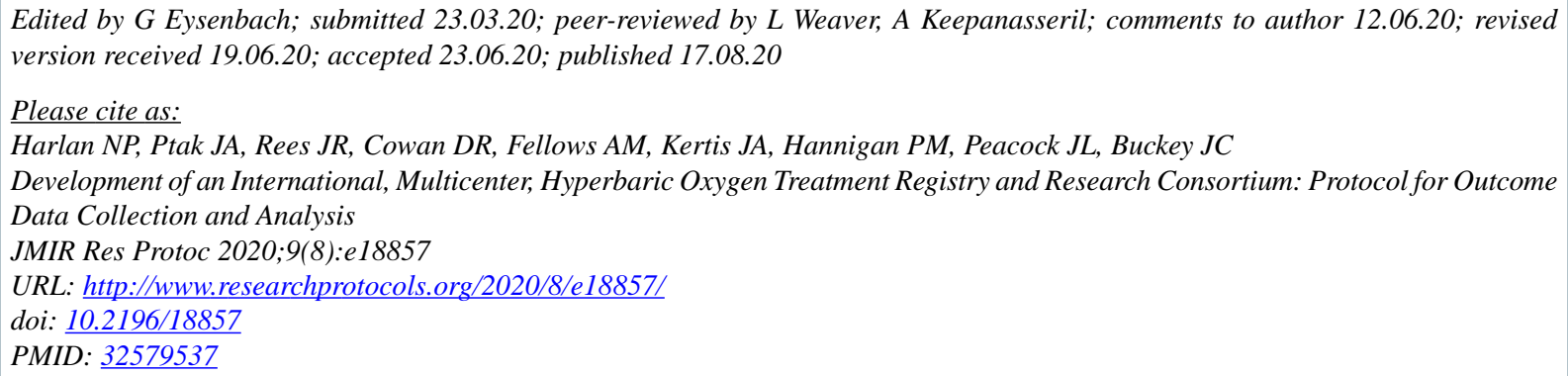

CNicole P Harlan, Judy A Ptak, Judy R Rees, Devin R Cowan, Abigail M Fellows, Judith A Kertis, Pamela M Hannigan, Janet L Peacock, Jay C Buckey. Originally published in JMIR Research Protocols (http://www.researchprotocols.org), 17.08.2020. This is an open-access article distributed under the terms of the Creative Commons Attribution License (https://creativecommons.org/licenses/by/4.0/), which permits unrestricted use, distribution, and reproduction in any medium, provided the original work, first published in JMIR Research Protocols, is properly cited. The complete bibliographic information, a link to the original publication on http://www.researchprotocols.org, as well as this copyright and license information must be included. 